\title{
Response to Fugard and Hines
}

\section{Professor Alice Sullivan, UCL.}

Abstract: This article replies to the responses to my article on "Sex and the Census: Why surveys should not conflate sex and gender identity" by Fugard and Hines. Fugard conflates sex itself with the characteristics associated with sex, such as finger length ratios, leading to the erroneous implication that sex is not a binary variable. Hines entirely misrepresents my argument, claiming that I have argued against asking respondents about gender identity, when I make clear that information on gender identity is useful, but cannot replace data on sex, and must be asked in addition to sex. Hines resorts to a series of ad hominems rather than engaging with the substance of the argument. Neither Fugard nor Hines is able to give a reason why we should not seek to collect accurate data on sex in the census or elsewhere.

Fugard (2020) argues that sex is a complex construct, inseparable from gender expression, and that it is a spectrum which should be measured via characteristics such as sex hormones and fingerlength ratios. The fundamental error here is to conflate sex itself with the characteristics associated with sex.

Since the number of ethnic categories in the census has changed over time, Fugard argues that the sex categories should similarly be allowed to change. The analogy is a poor one. The UK has experienced enormous demographic change since the first census in 1801, with the arrival of successive waves of immigrants from different parts of the world. Yet we remain mammals, and there has been no increase in the number of sexes. The analogy with race also fails because racial categories are socially constructed in the profound sense that we are all in fact mixed race. As I write during the Covid-19 pandemic, the higher mortality rate among males starkly illustrates that we need data on sex now just as much as we did in 1801.

Fugard's claim that sex is not an explanatory variable is novel. By definition, an explanatory variable is simply a predictor of the dependent variable. What counts as an explanatory variable is therefore up to the analyst. Fugard suggests that in a "comprehensive" model, sex differences would always be zero, implying that that sex differences will always be fully mediated in such a model. This strong claim is not justified. It is also irrelevant, because, even if the analyst is fundamentally interested in testing a mediation model, they will still need the sex variable. For example, If I want to know the extent to which the pay gap between the sexes is explained by labour market experience, I cannot assess this without accurate data on sex. In any case, Fugard's quest for the perfect model seems naïve. To quote a statistical aphorism "All models are wrong, but some are useful".

The concern Fugard expresses about the level of non-response to the sex question in the 2011 Census is misplaced, since, at $0.4 \%$, this is in fact reassuringly low (ONS 2012).

Fugard attempts to demonstrate that the effect of allowing the sex question to be answered in terms of gender identity would be minimal in practice through a worked example where a proportion of individuals are randomly recoded with the wrong sex. This misses the point that trans status may not be independent of other characteristics, including income. Indeed, it is contradictory to assume that trans status is not associated with other variables of interest while also stating that trans people are likely to suffer discrimination which we should be interested in monitoring. The most serious errors due to classifying trans individuals as the opposite sex will arise at the subgroup level - or at the level of intersectionality, for those who prefer that terminology. 
Turning to Hines (2020), I can only speculate as to whether she has failed to read and understand my paper (Sullivan 2020), or is willfully misrepresenting it. She asks "... why, for some feminists, is the inclusion of gender identity in Census 2021 a problem?". This "glaring question" is easily answered. It isn't. Data users have welcomed the new question on gender identity, but object to the proposed guidance to accompany the sex question, which conflates sex and gender identity.

Having entirely swerved the substance of the paper, Hines resorts to a series of ad hominems. She accuses me of paranoia and bad faith, and of being "trans exclusionary", and dismisses me as representing a "vocal minority". No evidence is provided for any of these assertions. The claim that people who believe that sex exists and is distinct from gender identity are a minority is constantly repeated by genderist extremists. This claim is both irrelevant to the substantive argument, and demonstrably false (Populus 2018).

Hines takes umbrage at my use of the term 'postmodernism'. To clarify, I see the label 'postmodern' as a polite shorthand for pseudo-intellectual mumbo-jumbo and anti-scientific values. I have no interest in the delineation of the various strands of thought within this worldview.

In conclusion, neither Fugard nor Hines is able to provide a reason why we should not seek to collect accurate data on sex within the census and beyond.

Finally, I would like to thank the editors for providing a forum for this exchange. This took courage, and I am hopeful that it may mark the beginning of the end of the "no debate" tactics that are causing grave damage to both data quality and the credibility of the social sciences.

\section{Bibliography}

Fugard, A. (2020). Should trans people be postmodernist in the streets but positivist in the spreadsheets? A reply to Sullivan . International Journal of Social Research Methodology. doi:10.1080/13645579.2020.1768343

Hines, S. (2020). Counting the cost of difference: A reply to Sullivan . International Journal of Social Research Methodology. doi:10.1080/13645579.2020.1768345.

ONS (2012) Item Edit and Imputation: Evaluation Report 2011 Census.

Populus (2018) https://fairplayforwomen.com/wpcontent/uploads/2018/11/gender recognition act-1.pdf

Sullivan, A. (2020). Sex and the census: why surveys should not conflate sex and gender identity . International Journal of Social Research Methodology. doi:10.1080/13645579.2020.1768346. 